\title{
ABCG2 expression in colorectal adenocarcinomas may predict resistance to irinotecan
}

\author{
HOANG DINH TUY $^{1}$, HISANORI SHIOMI ${ }^{1}$, KEN ICHI MUKAISHO ${ }^{2}$, SHIGEYUKI NAKA $^{1}$, \\ TOMOHARU SHIMIZU ${ }^{1}$, HIROMICHI SONODA ${ }^{1}$, EIJI MEKATA ${ }^{1}$, YOSHIHIRO ENDO ${ }^{1}$, \\ YOSHIMASA KURUMI $^{1}$, HIROYUKI SUGIHARA ${ }^{2}$, MASAJI TANI ${ }^{1}$ and TOHRU TANI $^{1}$ \\ Departments of ${ }^{1}$ Surgery and ${ }^{2}$ Pathology, Shiga University of Medical Science, Otsu, Shiga 520-2192, Japan
}

Received December 5, 2014; Accepted January 9, 2016

DOI: $10.3892 / 01.2016 .4937$

\begin{abstract}
Irinotecan is a key drug for patients with advanced and recurrent colorectal carcinoma. However, the efficacy of irinotecan is not sufficient; partly, as there is no useful marker to predict chemosensitivity to the drug. The aim of the present study was to evaluate whether the expression levels of adenosine triphosphate-binding cassette sub-family $\mathrm{G}$ (WHITE) member 2 (Junior blood group) (ABCG2) in primary colorectal tumors predict chemoresistance to irinotecan. Using the resected primary tumor specimens of 189 patients with colorectal cancer, the association between the immunohistochemical expression of ABCG2 protein and the results of the collagen gel droplet embedded culture drug sensitivity test, performed to evaluate the chemosensitivity to SN-38 (an active metabolite of irinotecan), was investigated. Among the 189 patients, 17 received irinotecan-based chemotherapy, and their responses and progression-free survival (PFS) were analyzed. The tumors of patients with increased ABCG2 expression accounted for $60 \%$ of the tumors examined, and were significantly more resistant to $\mathrm{SN}-38$, compared with patients with low ABCG2 expression $(\mathrm{P}<0.001)$. In a multivariate logistic regression analysis, increased expression of ABCG2 protein was an independent and significant predictor of resistance to $\mathrm{SN}-38$, increasing the risk of resistance by 12-fold. Increased expression of ABCG2 and a low sensitivity to $\mathrm{SN}-38$ was significantly associated with resistance to irinotecan-based chemotherapy ( $\mathrm{P}=0.01$ and 0.028 , respectively). The median PFS of patients with increased expression of ABCG2 was significantly shorter, compared with patients with low expression levels of ABCG2 (104 vs. 242 days; $\mathrm{P}=0.047)$. The increased immunohistochemical expression of ABCG2 in primary tumors may be a useful predictive biomarker of
\end{abstract}

Correspondence to: Dr Hisanori Shiomi, Department of Surgery, Shiga University of Medical Science, Seta Tsukinowa-cho, Otsu, Shiga 520-2192, Japan

E-mail: shiomi@belle.shiga-med.ac.jp

Key words: colorectal adenocarcinoma, ABCG2, irinotecan, drug resistance resistance to irinotecan-based chemotherapy for patients with recurrent or metastatic colorectal cancer.

\section{Introduction}

Colorectal cancer is the third most common malignancy and the fourth most lethal type of cancer in the world (1). Recurrence and metastases frequently occur in affected patients during the course of the disease, and chemotherapy is the major management strategy. Irinotecan is considered to be an essential component of first- and second-line treatments for metastatic or recurrent colorectal cancer, as 5-FU and leucovorin (FOLFIRI) \pm molecular target drug, although other regimens, such as FOLFOX and CapeOX \pm molecular target drug, are also considered good options (2). Current guidelines report that the selection of a specific chemotherapy regimen at present is solely based on the response to previous therapies or treatments in trials (2). Therefore, treatment results for patients with colorectal cancer have been far from satisfactory, with a response rate of $\sim 50 \%$ for irinotecan-based combinations (2).

Certain predictive markers for the response of colorectal cancer to chemotherapy have been identified, including microsatellite instability, thymidylate synthase, dihydropyrimidine dehydrogenase for 5-fluorouracil (5-FU), excision repair cross-complementing protein 1 for oxaliplatin and mutations in Kirsten rat sarcoma viral oncogene homolog, and B-Raf proto-oncogene, serine/threonine kinase for panitumumab and cetuximab $(3,4)$. In addition, numerous studies have been designed to indicate novel predictors of cellular response to irinotecan in vitro, including topoisomerase-I and -II, membrane transporter proteins, carboxylesterase, glucuronosyltransferases and proteasome $(5,6)$. However, these predictors have not been proved to be effective in clinical studies (7).

Multidrug resistance is a serious problem, and is considered one of the major causes of chemotherapy failure. Multidrug resistance is often associated with the overexpression of adenosine triphosphate-binding cassette (ABC) transporter proteins, including $\mathrm{ABCB} 1, \mathrm{ABCC} 1, \mathrm{ABCC} 2$ and ABCG2 (8). Expression of ABCG2 has been observed in the epithelial cells of the intestine, colon, liver canaliculi, renal tubules and placenta, where it eliminates anticancer drugs and ingested toxins (9). The association between overexpression of ABCG2, response to chemotherapy and prognosis has been 
reported for leukemia (10) and various solid tumors, including breast cancer (11), oral squamous cell carcinoma (12), esophageal cancer (13) and lung cancer (14). Irinotecan and its active metabolite, SN-38, are included among the transport substrates of ABCG2 (15). ABCG2 is abundant in the normal colon, and its expression is decreased in colorectal cancer. The downregulation of ABCG2 expression may have a role in tumorigenesis by enabling the accumulation of genotoxins and the overproduction of nitric oxide (16). The overexpression of ABCG2 protein in colon cancer cell lines has been associated with increased levels of resistance to SN-38 in vitro (17).

The aim of the present study was to assess whether the immunohistochemical expression of ABCG2 may be a potential predictor of the response to irinotecan-based treatment of patients with colorectal cancer. The results of the present study indicated that the increased expression of ABCG2 was associated with resistance to SN-38 in colorectal cancer and a negative response to irinotecan-based chemotherapy.

\section{Materials and methods}

Patients. The Ethics Committee of Shiga University of Medical Science (Otsu, Japan) approved this study. Signed informed consent was obtained prior to surgery from each of the 189 patients that underwent a colorectal resection at the Department of Surgery, Shiga University of Medical Science Hospital, between May 2004 and May 2012. All patients were chemotherapy-naive. The resected tumors were histologically confirmed as adenocarcinoma, and the chemosensitivities of the tumors to SN-38 and 5-FU were measured using the collagen gel droplet embedded culture drug sensitivity test (CD-DST). Among the 189 patients enrolled in the study, 17 underwent irinotecan-based chemotherapy for $\geq 2$ months. The cancer statuses of all 17 patients were recurrent and unresectable. The patients received no surgical or radiation interventions during the period of chemotherapy. A total of 13 patients received the FOLFIRI regimen; Irinotecan at a dose of $120 \mathrm{mg} / \mathrm{m}^{2}$ as a $2 \mathrm{~h}$ intravenous (i.v.) infusion on day 1; Leucovorin was given at a dose of $400 \mathrm{mg} / \mathrm{m}^{2}$ as a 2-h i.v. infusion, followed by $5-\mathrm{FU} 400 \mathrm{mg} / \mathrm{m}^{2}$ as an i.v. bolus, and then, 2,400 $\mathrm{mg} / \mathrm{m}^{2}$ as a 22-h continuous i.v. infusion, on days 1 and 2, repeated every 2 weeks (18). A further 4 patients received the IRIS regimen; Irinotecan at a dose of $150 \mathrm{mg} / \mathrm{m}^{2}$ as a $1.5-\mathrm{h}$ i.v. infusion on day 1 , followed by S-1 $100 \mathrm{mg} /$ day for 14 days perorally, repeated every 3 weeks. The Bevacizumab dose was $7.5 \mathrm{mg} / \mathrm{kg}$ and was administered i.v. every 2 weeks, initially over $90 \mathrm{~min}$. The best responses across all time points, which were evaluated 2 months following the initial administration of the irinotecan-based regimen, were used for classification according to the Response Evaluation Criteria In Solid Tumors guideline, version 1.1 (19), and assigned complete response (CR), partial response (PR), stable disease (SD) or progressive disease (PD).

$C D$-DST. CD-DST was used to evaluate the sensitivity of cancer tissue to SN-38. Briefly, $5 \mathrm{~mm}$ cube of colorectal cancer specimens obtained by surgery were minced by surgical knife, and digested with collagenase, and the dispersed cancer cells were incubated in a collagen gel coated flask. Only the viable cells adhering to the collagen gel layer were collected and added to the reconstructed type I collagen solution (Cellmatrix Type CD; Kurabo Industries, Ltd., Osaka, Japan). SN-38 (0.03 $\mu \mathrm{g} / \mathrm{ml}$; LKT Laboratories, Inc., St Paul, MN, USA) and 5-FU ( $1 \mu \mathrm{g} / \mathrm{ml}$; Kyowa Hakko Kirin Co., Ltd., Tokyo, Japan) were added to each well. The plate was then incubated for $24 \mathrm{~h}$ at $37^{\circ} \mathrm{C}$. Subsequent to the removal of the medium containing the anticancer drug, each well was incubated with PCM-2 medium (Kurabo Industries, Ltd.) for 7 days. Neutral red was then added to stain the colonies in the collagen gel droplets, which were next fixed with formalin. The in vitro chemosensitivity effect was expressed as a ratio of the total colony volume of the treated group $(\mathrm{T})$ to that of the control group (C) (T/C ratio) (20). A T/C ratio of $\leq 60 \%$ was regarded as sensitive.

Immunohistochemical staining. All specimens were archived as formalin-fixed and paraffin-embedded tissues. Sections (3- $\mu \mathrm{m}$ thick) were cut and immunostained using the Ventana Discovery XT staining system (Ventana Medical Systems, Inc., Tucson, AZ, USA). Normal and cancerous tissues from the same patient were mounted onto the same slide to ensure identical conditions. Slides were then incubated with a primary anti-ABCG2 antibody (clone BXP-21 mouse anti-human monoclonal antibody; dilution, 1:500; catalog no. MAB4146; Merck Millipore, Darmstadt, Germany) at $37^{\circ} \mathrm{C}$ for $32 \mathrm{~min}$, followed by incubation with Discovery ${ }^{\mathrm{TM}}$ Universal Secondary Antibody, a biotinylated immunoglobulin (lg) cocktail of goat anti-mouse $\lg \mathrm{G}$, goat anti-mouse $\lg \mathrm{M}$, goat anti-rabbit $\lg \mathrm{G}$ and protein block (ready for use; catalog no. 760-4205; Ventana Medical Systems, Inc.). The immunological reaction was visualized with 3,3'-diaminobenzidine chromogen (DAB Map Kit; Ventana Medical Systems, Inc.), followed by counterstaining with hematoxylin. Sections were dehydrated and cover slips were mounted.

Stained slides were examined independently by two researchers from the Departments of Surgery and Pathology of Shiga University of Medical Science (Otsu, Japan). The staining intensity of positive cell membranes was classified as negative (no staining), 0 ; weak, 1; moderate, 2; or intense (as strong as in normal colonocytes), 3. The proportion of total positive cancer cells with membranous positivity was scored as follows: $<5 \%, 0 ; 5-25 \%, 1 ; 26-50 \%, 2 ; 51-75 \%, 3$; or $>75 \%, 4$.

ABCG2 expression was determined by multiplication of the values for intensity and proportion, and was classified as lowor high-expression for scores of $0-8$ or 9-12, respectively (21). For heterogeneous signals, the results were based on the most intensely stained group of cells. The negative control was processed by replacing the primary antibody against ABCG2 with phosphate-buffered saline.

Statistical analysis. SPSS software, version 17.0 (SPSS, Inc., Chicago, IL, USA) and Stata software version 10.1 (StataCorp LP, College Station, TX, USA) were used for statistical analyses. In order to compare the differences across stratified groups, the $t$-test or Wilcoxon test was performed for continuous variables, and the $\chi^{2}$ test or Fisher's exact test was performed for categorical variables, as appropriate. The univariate and multivariate logistic regression or Pearson's $\chi^{2}$ statistic were used to analyze the effect of clinicopathological factors and ABCG2 expression on SN-38 sensitivity, or 

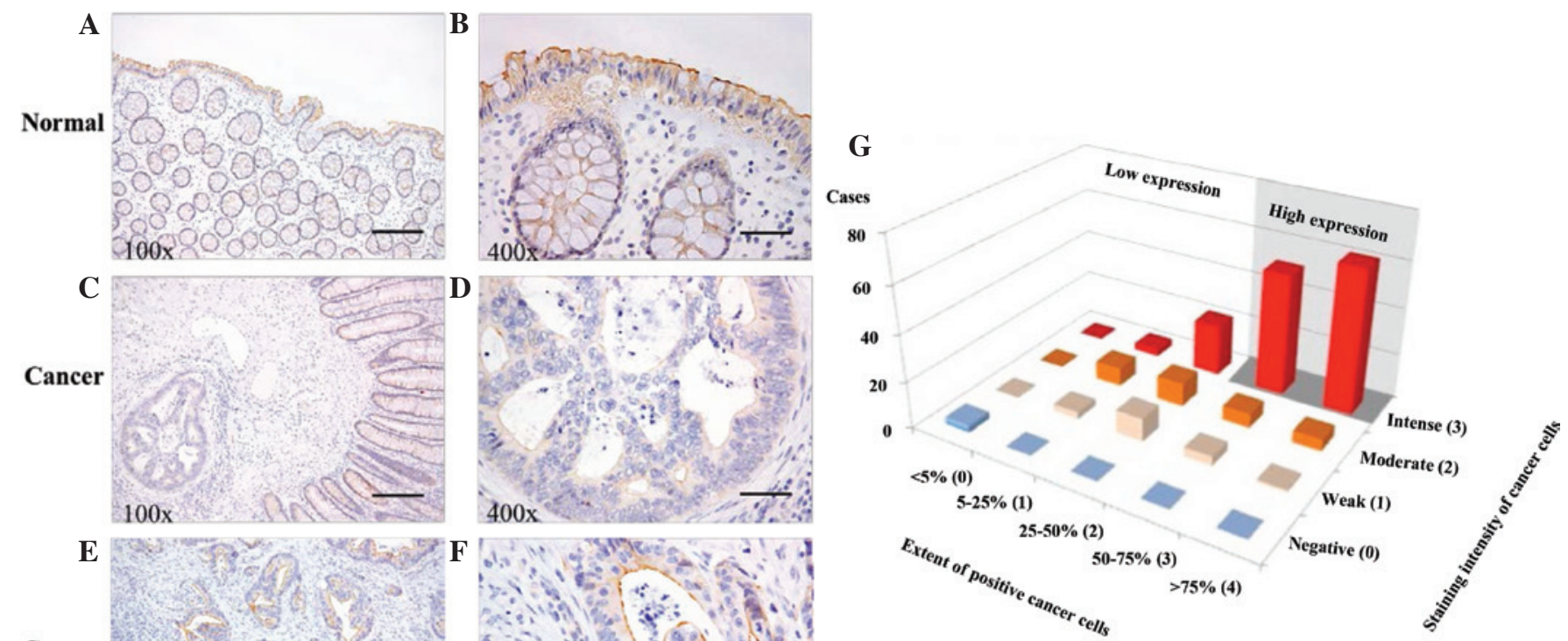

Cancer
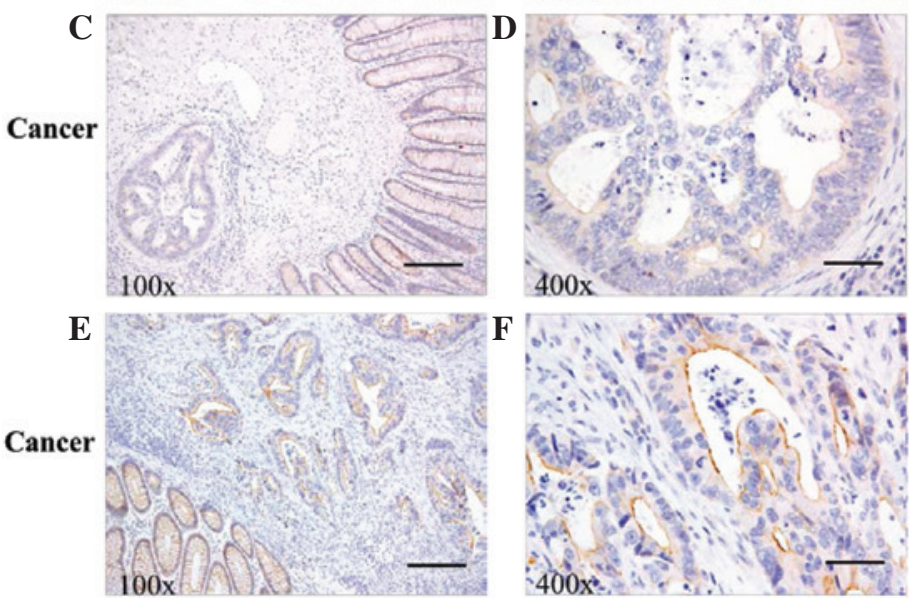

Figure 1. ABCG2 expression was evaluated by immunohistochemistry in normal colon and colorectal cancer tissues. (A and B) ABCG2 protein signal (brown) was strongest along the brush border membranes of normal colonocytes (patient with colon cancer). (C and D) ABCG2 expression in cancerous gland (left side) is weaker than that of normal ground surrounding the tumor (right side). (Low expression group, colon cancer). (E and F) Intense ABCG2 expression in the cancerous glands (right upper side) is similar to normal colonocytes around the tumor (left lower side) (High expression group, rectal cancer). Scale bar, $200 \mu \mathrm{m}$ and magnification, x100 in panels A, C and E. Scale bar, $50 \mu \mathrm{m}$ and magnification, x400 in panels B, D and F. (G) ABCG2 expression was quantified by multiplication of the scores for intensity and proportion, and patients were classified into low- or high-expression groups, according to scores of 0-8 or 9-12, respectively. ABCG2, adenosine triphosphate-binding cassette sub-family G (WHITE) member 2 (Junior blood group).

the discrepancy between these variables, respectively; variables with $\mathrm{P}<0.25$ were selected as candidates for inclusion in the multivariate model (22). A 95\% confidence interval (CI) for prevalance ratio (PR) were calculated with standard errors estimated by the Wald test. Overall survival (OS) was defined as the time between the date of initial administration of the irinotecan-based regimen and mortality or final follow-up. Progression-free survival (PFS) was defined as the time between the date of initial administration of the irinotecan-based regimen and recurrence or final follow-up. The survival curves were calculated according to the Kaplan-Meier method, and differences between curves were assessed using the generalized Wilcoxon test. $\mathrm{P}<0.05$ was considered to indicate a statistically significant difference.

\section{Results}

Expression of $A B C G 2$ in colorectal cancer tissues. In the normal colon mucosa samples, the expression of ABCG2 was increased along the brush border membranes of normal colonocytes (Fig. 1A and B). High expression in the tumor was defined as non-intense expression or low proportion of ABCG2 positivity (Fig. 1C and D) and the tumor was defined as intense expression in $50 \%$ or more of the cancer cells, and low expression (Fig. 1E and F) The patients were classified into low-expression (76 patients; $40 \%$ ) or high-expression (113 patients; 60\%) groups, of which the median immunohistochemistry scores were $4.21 \pm 0.25$ and $10.55 \pm 0.15$, respectively. A three-dimensional distribution of the proportion of positive cancer cells and signal intensities are shown in Fig. 1G.
Association between $S N-38$ response, ABCG2 expression and clinicopathological factors in patients with colorectal cancer. The clinicopathological factors of the 189 patients are presented in Table I. Briefly, 119 patients possessed colon cancer and 70 possessed rectal cancer. The ages of the patients ranged between 33 and 88 years (median, 65 years). Moderate differentiation (72\%) and stage 3 or $4(54 \%)$ tumors were identified in the majority of patients. ABCG2 expression in rectal cancer was significantly increased, compared with expression in colon cancer $(\mathrm{P}=0.019)$. The median $\mathrm{SN}-38 \mathrm{~T} / \mathrm{C}$ ratio was significantly increased in the high-expression group, compared with the low-expression group $(\mathrm{P}<0.001)$. No significant association between the expression levels of ABCG2 and any other clinicopathological factors studied was observed, including age, gender, histological type, tumor invasion, lymph node metastasis, distant metastasis, lymphatic invasion, venous invasion and stage of the tumor.

Associations between sensitivity to SN-38 and clinicopathological factors were analyzed as categorical variables in a univariate analysis (Table II). Patients with increased expression of ABCG2 were significantly more resistant to SN-38, compared with patients with low expression of ABCG2 $(\mathrm{P}<0.001)$. The sensitivity of increased expression of $\mathrm{ABCG} 2$ to predict the low response to SN-38 by CD-DST was $82 \%$, and the specificity was $73 \%$. Other factors, including age, gender, differentiation, stage grouping, tumor depth, lymph node metastasis, distant metastasis, lymphatic invasion and venous invasion, did not associate with sensitivity to SN-38. Two selected variables, namely location of the tumor and expression of $\mathrm{ABCG} 2$, were analyzed in a multivariate 
Table I. Clinicopathological factors and protein expression levels of adenosine triphosphate-binding cassette sub-family $\mathrm{G}$ (WHITE) member 2 (Junior blood group) in 189 patients with colorectal cancer.

\begin{tabular}{|c|c|c|c|c|}
\hline Characteristics & $\begin{array}{l}\text { All patients, } \\
\text { n (\%) }\end{array}$ & $\begin{array}{l}\text { Low-expression } \\
\text { group, n }(\%)\end{array}$ & $\begin{array}{l}\text { High-expression } \\
\text { group, } \mathrm{n}(\%)\end{array}$ & P-value \\
\hline Total & $189(100)$ & $76(40)$ & $113(60)$ & \\
\hline \multicolumn{5}{|l|}{ Age, years } \\
\hline Median & 65 & 64 & 66 & \multirow[t]{2}{*}{$0.271^{\mathrm{a}}$} \\
\hline Range & $33-88$ & $33-88$ & $43-86$ & \\
\hline \multicolumn{5}{|l|}{ Gender } \\
\hline Female & $77(41)$ & $29(38)$ & $48(42)$ & \multirow[t]{2}{*}{$0.659^{\mathrm{b}}$} \\
\hline Male & $112(59)$ & $47(62)$ & $65(58)$ & \\
\hline \multicolumn{5}{|l|}{ Tumor location } \\
\hline Colon & $119(63)$ & $56(74)$ & $63(56)$ & \multirow[t]{2}{*}{$0.019^{\mathrm{b}}$} \\
\hline Rectum & $70(37)$ & $20(26)$ & $50(44)$ & \\
\hline \multicolumn{5}{|l|}{ Differentiation } \\
\hline Well & $39(21)$ & $15(20)$ & $24(21)$ & \multirow[t]{3}{*}{$0.733^{\mathrm{b}}$} \\
\hline Moderate & $136(72)$ & $54(71)$ & $82(73)$ & \\
\hline Poor & $14(7)$ & $7(9)$ & $7(6)$ & \\
\hline \multicolumn{5}{|l|}{ Stage grouping } \\
\hline Duke's A & $87(46)$ & $35(46)$ & $52(46)$ & \multirow[t]{2}{*}{$1.000^{\mathrm{b}}$} \\
\hline Duke's B, C & $102(54)$ & $41(54)$ & $61(54)$ & \\
\hline \multicolumn{5}{|l|}{ Tumor depth } \\
\hline $\mathrm{pT} 1,2$ & $35(19)$ & $9(12)$ & $26(23)$ & \multirow[t]{2}{*}{$0.081^{\mathrm{b}}$} \\
\hline pT3,4 & $154(81)$ & $67(88)$ & $87(77)$ & \\
\hline \multicolumn{5}{|c|}{ Lymph node metastasis } \\
\hline N0 & $94(50)$ & $38(50)$ & $56(50)$ & \multirow[t]{2}{*}{$1.000^{\mathrm{b}}$} \\
\hline $\mathrm{N} 1,2$ & $95(50)$ & $38(50)$ & $57(50)$ & \\
\hline \multicolumn{5}{|l|}{ Distant metastasis } \\
\hline M0 & $156(83)$ & $60(79)$ & $96(85)$ & \multirow[t]{2}{*}{$0.383^{\mathrm{b}}$} \\
\hline M1 & $33(17)$ & $16(21)$ & $17(15)$ & \\
\hline \multicolumn{5}{|l|}{ Lymphatic invasion } \\
\hline Ly0,1 & $133(70)$ & $50(66)$ & $83(73)$ & \multirow[t]{2}{*}{$0.333^{\mathrm{b}}$} \\
\hline Ly2,3 & $56(30)$ & $26(34)$ & $30(27)$ & \\
\hline \multicolumn{5}{|l|}{ Venous invasion } \\
\hline V0,1 & $126(67)$ & $49(64)$ & $77(68)$ & \multirow[t]{2}{*}{$0.714^{\mathrm{b}}$} \\
\hline $\mathrm{V} 2,3$ & $63(33)$ & $27(36)$ & $36(32)$ & \\
\hline \multicolumn{5}{|l|}{ SN-38 effect, T/C } \\
\hline Median & 66 & 55 & 73 & \multirow[t]{2}{*}{$<0.001^{\mathrm{a}}$} \\
\hline Range & $21-100$ & $21-100$ & $32-100$ & \\
\hline Sensitive, $\mathrm{T} / \mathrm{C}<60$ & $77(41)$ & $56(74)$ & $21(19)$ & $<0.001^{\mathrm{b}}$ \\
\hline Resistant, $\mathrm{T} / \mathrm{C} \geq 60$ & $112(59)$ & $20(26)$ & $92(81)$ & \\
\hline
\end{tabular}

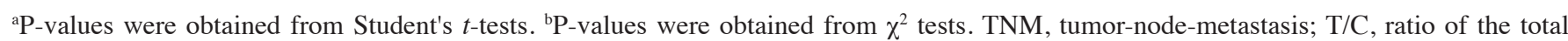
colony volume of the treated group (T) to that of the control group (C).

regression model. Patients with increased expression of ABCG2 were the strongest indicators of resistance to SN-38 [prevalence ratio (PR), 11.77; 95\% confidence interval (CI), 5.83-23.76; $\mathrm{P}<0.001)$.

ABCG2 expression and clinical response to irinotecan-based chemotherapy. Eligibility criteria for tumor response to irinotecan-based regimens were identified in 17 patients, of which, 5 (29\%) were classified as PR and $12(71 \%)$ as non-responders, including 11 SD and 1 PD. The patient and tumor characteristics for responders and non-responders are shown in Table III. There were no significant differences between the two groups, with the exception of the expression levels of ABCG2 and 
Table II. Multivariate analysis of clinicopathological factors and SN-38 sensitivity in 189 patients with colorectal cancer.

\begin{tabular}{|c|c|c|c|c|c|}
\hline \multirow[b]{2}{*}{ Factors } & \multirow{2}{*}{$\begin{array}{c}\text { Sensitive, } \\
\mathrm{n}(\%)\end{array}$} & \multirow{2}{*}{$\begin{array}{l}\text { Resistant, } \\
\mathrm{n}(\%)\end{array}$} & \multirow{2}{*}{$\begin{array}{c}\text { Univariate } \\
\text { analysis } \\
\text { P-value }\end{array}$} & \multicolumn{2}{|c|}{ Multivariate analysis } \\
\hline & & & & Adjusted PR (95\% CI) & P-value ${ }^{b}$ \\
\hline Total & $77(41)$ & $112(59)$ & & & \\
\hline \multicolumn{6}{|l|}{ Age, years } \\
\hline$<65$ & $40(52)$ & $59(53)$ & 1.000 & & \\
\hline$\geq 65$ & $37(48)$ & $53(47)$ & & & \\
\hline \multicolumn{6}{|l|}{ Gender } \\
\hline Female & $35(45)$ & $42(38)$ & 0.346 & & \\
\hline Male & $42(55)$ & $70(63)$ & & & \\
\hline \multicolumn{6}{|c|}{ Tumor location } \\
\hline Colon & $55(71)$ & $64(57)$ & 0.065 & Ref & 0.446 \\
\hline Rectum & $22(29)$ & $48(43)$ & & $1.33(0.63-2.77)$ & \\
\hline \multicolumn{6}{|c|}{ Differentiation } \\
\hline Well & $16(21)$ & $23(21)$ & 0.756 & & \\
\hline Moderate & $54(70)$ & $82(73)$ & & & \\
\hline Poor & $7(9)$ & $7(6)$ & & & \\
\hline \multicolumn{6}{|c|}{ Stage grouping } \\
\hline Duke's A & $36(47)$ & $51(46)$ & 0.987 & & \\
\hline Duke's B,C & $41(53)$ & $61(54)$ & & & \\
\hline \multicolumn{6}{|l|}{ Tumor depth } \\
\hline pT1,2 & $11(14)$ & $24(21)$ & 0.093 & & \\
\hline pT3,4 & $66(86)$ & $88(79)$ & & & \\
\hline \multicolumn{6}{|c|}{ Lymph node metastasis } \\
\hline N0 & $40(52)$ & $54(48)$ & 0.722 & & \\
\hline $\mathrm{N} 1,2$ & $37(48)$ & $58(52)$ & & & \\
\hline \multicolumn{6}{|c|}{ Distant metastasis } \\
\hline M0 & $64(83)$ & $92(82)$ & 1.000 & & \\
\hline M1 & $13(17)$ & $20(18)$ & & & \\
\hline \multicolumn{6}{|c|}{ Lymphatic invasion } \\
\hline Ly0,1 & $53(69)$ & $80(71)$ & 0.824 & & \\
\hline Ly2,3 & $24(31)$ & $32(29)$ & & & \\
\hline \multicolumn{6}{|c|}{ Venous invasion } \\
\hline V0,1 & $53(69)$ & $73(65)$ & 0.714 & & \\
\hline V2,3 & $24(31)$ & $39(35)$ & & & \\
\hline \multicolumn{6}{|c|}{ ABCG 2 expression } \\
\hline Low & $56(73)$ & $20(18)$ & $<0.001$ & Ref & $<0.001$ \\
\hline High & $21(27)$ & $92(82)$ & & $11.77(5.83-23.76)$ & \\
\hline
\end{tabular}

${ }^{\text {aP }}$-values were obtained from $\chi^{2}$ tests. ${ }^{\text {} P}$-values were obtained from Wald tests. TNM, tumor-node-metastasis; PR, prevalence ratio; CI, confidence interval; ABCG2, adenosine triphosphate-binding cassette sub-family G (WHITE) member 2 (Junior blood group); Ref, reference.

the effect of SN-38 by CD-DST. Increased expression of ABCG2 was observed in 11 of 12 non-responders, whereas 4 of 5 responders exhibited decreased expression of ABCG2. The sensitivity of increased ABCG2 expression to predict the resistance to irinotecan-based chemotherapy was $92 \%$, and the specificity was $80 \%$. The results of CD-DST indicated sensitivity to $\mathrm{SN}-38$ in 4 of 5 responders (80\%), compared with 2 of 12 non-responders (17\%); the difference between which was significant $(\mathrm{P}=0.028)$.
The association between treatment characteristics and PFS is shown in Table IV. The median PFS of the responder group was significantly longer, compared with the non-responder group (372 vs. 104 days; $\mathrm{P}=0.013$ ). The median PFS was significantly longer in the patients with low-expression of ABCG2 than those with high-expression of ABCG2 (242 vs. 104 days; $P=0.047$, Fig. 2). The median PFS of the 17 patients sensitive to SN-38 tended to be longer than the median PFS of resistant patients; however, this result was not statistically 
Table III. Clinicopathological characteristics and response to irinotecan-based chemotherapy of 17 patients with colorectal cancer.

\begin{tabular}{|c|c|c|c|c|}
\hline Characteristics & $\begin{array}{l}\text { All patients, } \\
\text { n }(\%)\end{array}$ & $\begin{array}{l}\text { Responders }(\mathrm{n}=5) \\
\mathrm{n}(\%)\end{array}$ & $\begin{array}{l}\text { Non-responders }(\mathrm{n}=12) \text {, } \\
\mathrm{n}(\%)\end{array}$ & P-value \\
\hline \multicolumn{5}{|l|}{ Age, years } \\
\hline Median & 60 & 67 & 58 & \multirow[t]{2}{*}{$0.246^{\mathrm{a}}$} \\
\hline Range & $33-77$ & $56-76$ & $33-77$ & \\
\hline \multicolumn{5}{|l|}{ Gender } \\
\hline Female & $6(35)$ & $1(20)$ & $5(42)$ & \multirow[t]{2}{*}{$0.600^{\mathrm{b}}$} \\
\hline Male & $11(65)$ & $4(80)$ & $7(58)$ & \\
\hline \multicolumn{5}{|l|}{ Tumor location } \\
\hline Colon & $8(47)$ & $3(60)$ & $5(42)$ & \multirow[t]{2}{*}{$0.620^{\mathrm{b}}$} \\
\hline Rectum & $9(53)$ & $2(40)$ & $7(58)$ & \\
\hline \multicolumn{5}{|l|}{ Differentiation } \\
\hline Well & $0(0)$ & $0(0)$ & $0(0)$ & \multirow[t]{3}{*}{$0.515^{\mathrm{b}}$} \\
\hline Moderate & $15(88)$ & $4(80)$ & $11(92)$ & \\
\hline Poor & $2(12)$ & $1(20)$ & $1(8)$ & \\
\hline \multicolumn{5}{|l|}{ Stage grouping } \\
\hline Duke's A & $1(6)$ & $0(0)$ & $1(8)$ & \multirow[t]{3}{*}{$1.000^{\mathrm{b}}$} \\
\hline Duke's B & $4(24)$ & $1(20)$ & $3(25)$ & \\
\hline Duke's C & $12(70)$ & $4(80)$ & $8(57)$ & \\
\hline \multicolumn{5}{|l|}{ No. of metastatic sites } \\
\hline 1 & $7(41)$ & $2(40)$ & $5(42)$ & \multirow[t]{3}{*}{$1.000^{\mathrm{b}}$} \\
\hline 2 & $8(47)$ & $3(60)$ & $5(42)$ & \\
\hline 3 & $2(12)$ & $0(0)$ & $2(17)$ & \\
\hline \multicolumn{5}{|l|}{ Line of chemotherapy } \\
\hline $1 \mathrm{st}$ & $4(23)$ & $1(20)$ & $3(25)$ & \multirow[t]{4}{*}{$0.744^{\mathrm{b}}$} \\
\hline 2nd & $6(35)$ & $2(40)$ & $4(33)$ & \\
\hline $3 \mathrm{rd}$ & $4(23)$ & $2(40)$ & $2(17)$ & \\
\hline Other & $3(18)$ & $0(0)$ & $3(25)$ & \\
\hline \multicolumn{5}{|c|}{ Chemotherapy regimen } \\
\hline FOLFIRI & $13(76)$ & $4(80)$ & $9(75)$ & \multirow[t]{2}{*}{$1.000^{\mathrm{b}}$} \\
\hline IRIS & $4(23)$ & $1(20)$ & $3(25)$ & \\
\hline \multicolumn{5}{|l|}{ Bevacizumab } \\
\hline Without & $8(47)$ & $3(60)$ & $5(42)$ & \multirow[t]{2}{*}{$0.620^{\mathrm{b}}$} \\
\hline With & $9(53)$ & $2(40)$ & $7(58)$ & \\
\hline \multicolumn{5}{|l|}{ ABCG2 expression } \\
\hline Low & $5(29)$ & $4(80)$ & $1(8)$ & \multirow[t]{2}{*}{$0.010^{\mathrm{b}}$} \\
\hline High & $12(71)$ & $1(20)$ & $11(92)$ & \\
\hline \multicolumn{5}{|l|}{ SN-38 effect, T/C } \\
\hline Median & 69 & 59 & 73 & \multirow[t]{2}{*}{$0.113^{\mathrm{a}}$} \\
\hline Range & $31-100$ & $31-87$ & $32-100$ & \\
\hline Sensitive, $\mathrm{T} / \mathrm{C}<60$ & $6(35)$ & $4(80)$ & $2(17)$ & \multirow[t]{2}{*}{$0.028^{\mathrm{b}}$} \\
\hline Resistant, $\mathrm{T} / \mathrm{C} \geq 60$ & $11(65)$ & $1(20)$ & $10(83)$ & \\
\hline \multicolumn{5}{|l|}{ 5-FU effect, T/C } \\
\hline Median & 71 & 64 & 74 & $0.342^{\mathrm{a}}$ \\
\hline Range & $32-100$ & $32-81$ & $42-100$ & \\
\hline Sensitive, $\mathrm{T} / \mathrm{C}<60$ & $3(18)$ & $1(20)$ & $2(17)$ & $1.000^{\mathrm{b}}$ \\
\hline Resistant, $\mathrm{T} / \mathrm{C} \geq 60$ & $14(82)$ & $4(80)$ & $10(83)$ & \\
\hline
\end{tabular}

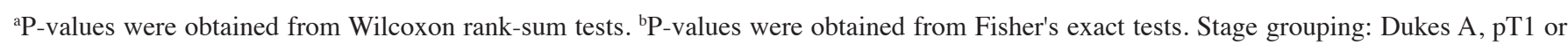
pT2, and N0; Dukes B, pT3 or pT4, and N0; Dukes C, any pT, and N1 or N2; FOLFIRI, leucovorin, fluorouracil and irinotecan; IRIS, oral fluorouracil and irinotecan; ABCG2, adenosine triphosphate-binding cassette sub-family G (WHITE) member 2 (Junior blood group); T/C, ratio of the total colony volume of the treated group $(\mathrm{T})$ to that of the control group $(\mathrm{C})$; FU, fluorouracil. 
Table IV. Treatment characteristics and association with PFS following irinotecan-based chemotherapy in 17 patients with colorectal cancer.

PFS following irinotecan-based chemotherapy

Characteristics $\quad$ Patients, n (\%) Median PFS, days

Line of chemotherapy

$1 \mathrm{st}$

4 (23)

176

0.267

2nd

6 (35)

104

3 rd

4 (23)

242

Other

3 (18)

104

Chemotherapy regimen

\section{FOLFIRI \\ IRIS}

13 (76)

4 (23)

8 (47)

9 (53)

5 (29)

$12(71)$

$6(35)$

$11(65)$

3 (18)

$14(82)$

5 (29)

$12(71)$

Response

Responder
Non-responder
167

104

104

176

242

104

242

110

200

0.381

116

372

104

0.773

0.061

PFS, progression-free survival; FOLFIRI, leucovorin, fluorouracil and irinotecan; IRIS, oral fluorouracil and irinotecan; ABCG2, adenosine triphosphate-binding cassette sub-family G (WHITE) member 2 (Junior blood group); T/C, ratio of the total colony volume of the treated group (T) to that of the control group (C); FU, fluorouracil.

significant (242 vs. 110 days; $\mathrm{P}=0.061$ ). Other factors, including the line or content of the chemotherapy and sensitivity to 5-FU, did not affect the median PFS. The median OS of the 17 patients was 554 days. The median OS of the patients with increased and decreased ABCG2 expression were 449 days and 554 days, respectively, which showed no significant difference $(\mathrm{P}=0.505)$.

\section{Discussion}

The resistance of cancer cells with ABCG2 overexpression to SN-38 is most likely due to the efflux transportation of SN-38 and SN-38 glucuronide out of the cells (23). ABCG2 has been the subject of numerous studies on leukemia and several solid tumors; however, there are numerous conflicting reports regarding the association between $\mathrm{ABCG} 2$ expression and the outcome of chemotherapy or survival $(24,25)$. The present study investigated whether ABCG2 expression is associated with SN-38 resistance in human colorectal cancer, and demonstrated that the increased expression of ABCG2 may predict resistance to $\mathrm{SN}-38$ treatment, with a sensitivity of $82 \%$, and

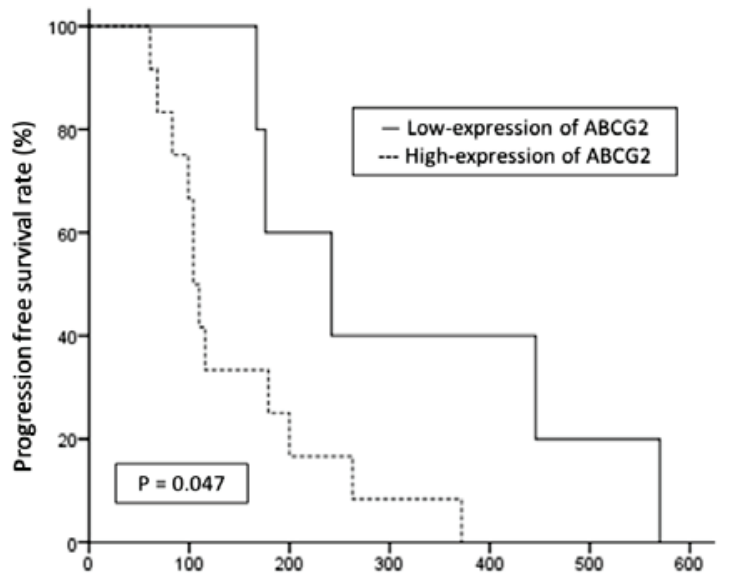

Period after beginning of irinotecan-based chemotherapy (days)

Figure 2. Kaplan-Meier curves for PFS of patients with colorectal cancer, according to their expression levels of adenosine triphosphate-binding cassette sub-family G (WHITE) member 2 (Junior blood group). The median PFS of the low-expression group was significantly longer than that of the high-expression group ( 242 vs. 104 days, $\mathrm{P}=0.047$ ). $\mathrm{PFS}$, progression-free survival; ABCG2, adenosine triphosphate-binding cassette sub-family G (WHITE) member 2 (Junior blood group). 
the lack of response to irinotecan-based chemotherapy, with a sensitivity of $92 \%$. Patients with primary tumors that demonstrated increased ABCG2 expression were at an increased (11.77-fold) risk of a negative response to irinotecan-based chemotherapy $(\mathrm{P}<0.001)$.

Deitrich et al (26) showed that the downregulation of ABCG2 led to the accumulation of carcinogens, including 2-amino-1-methyl-6-phenylimidazo [4,5-b] pyridine, in the colorectal adenomas of mice and humans, and suggested that this may promote the adenoma-carcinoma sequence. Gupta et al (16) reported that the expression of ABCG2 mRNA and protein was abundant in the normal colon and decreased in colon cancer tissue. However, the possibility of alterations in ABCG2 expression during the progression of a carcinoma remained to be clarified. The present study demonstrated that $\sim 60 \%$ of patients that possessed tumors belonged to the high-ABCG2-expression group.

A few studies have investigated the expression of ABCG2 mRNA in human colorectal cancer, but to the best of our knowledge, none have reported associations with the effects of chemotherapy, including irinotecan $(17,27)$. Associations between the increased expression of ABCG2 with lymph node metastasis and the clinical stage of breast cancer (28), and with poor differentiation in glioma cells (29), have been reported. However, the present study did not indicate any significant associations with clinicopathological factors, with the exception of the precise location of the primary tumor. The expression level of ABCG2 in rectal cancer was significantly increased compared with in colon cancer $(\mathrm{P}=0.019)$. In addition, the number of patients whose tumors were resistant to SN-38 was increased for rectal cancer compared with colon cancer, although this was not statistically significant $(\mathrm{P}=0.065)$. No evidence was identified that explained this result; therefore, future investigation is required in order to understand this phenomenon.

Topoisomerase I mutations (30), ABCG2 overexpression (17) in cancer cell lines and gene expression profiles (31) in human colorectal cancer tissue have been suggested to be involved in the development of resistance to irinotecan. The expression of topoisomerase I has been investigated as a predictive factor for patient response to irinotecan in vitro (32), but no effects on response, time to progression or OS have been identified in clinical studies (33). In the present study, despite having only 17 eligible patients, the increased expression of ABCG2 was significantly associated with resistance to irinotecan-based chemotherapy $(\mathrm{P}=0.01)$ and a shorter PFS $(\mathrm{P}=0.047)$. These data suggest that ABCG2 may be useful as a biomarker to predict chemoresistance to SN-38 of primary colorectal cancer tissues. Patients with recurrent or metastatic colorectal cancer that possess primary tumors with increased ABCG2 expression may, therefore, avoid irinotecan-based chemotherapy, enabling treatment with other regimens instead. Similarly, patients with decreased ABCG2 expression may possibly receive more benefits from irinotecan-based regimens compared patients with increased expression. The median OS of the patients with low-ABCG2-expression ( $\mathrm{n}=5$ ) was not significantly different compared with those with high-expression $(\mathrm{n}=12)(\mathrm{P}=0.505)$. This may be due to the majority of patients that were judged as PD receiving additional lines of chemotherapy, following the irinotecan-based chemotherapy.
ABCG2 immunohistochemical staining of primary colorectal cancer tissues is easy to perform, and may provide information regarding the chemosensitivity of patients to irinotecan. Prospective studies with increased numbers of patients are required to confirm this hypothesis. An inhibitor of ABCG2 may possibly be used as an additional agent with irinotecan-based regimens in patients defined as irinotecan-resistant due to the increased expression of ABCG2. In conclusion, the increased expression of ABCG2 may be involved in $\mathrm{SN}-38$ resistance in colorectal cancer and may be a useful predictive biomarker for use in patients that are under consideration for treatment with irinotecan-based chemotherapy.

\section{Acknowledgements}

The authors would like to thank Ms. Ikuko Arikawa, Ms. Ai Kenmochi and Ms. Miho Yamamoto from the Department of Surgery, Shiga University of Medical Science (Otsu, Japan), for their expert technical assistance in immunohistochemical staining of ABCG2.

\section{References}

1. Ferlay J, Shin HR, Bray F, Forman D, Mathers C and Parkin DM: Estimates of worldwide burden of cancer in 2008: GLOBOCAN 2008. Int J Cancer 127: 2893-2917, 2010.

2. Benson AB 3rd, Bekaii-Saab T, Chan E, Chen YJ, Choti MA, Cooper HS, Engstrom PF, Enzinger PC, Fakih MG, Fenton MJ, et al; National Comprehensive Cancer Network: Localized colon cancer, version 3.2013: Featured updates to the NCCN Guidelines. J Natl Compr Canc Netw 11: 519-528, 2013.

3. Pritchard CC and Grady WM: Colorectal cancer molecular biology moves into clinical practice. Gut 60: 116-129, 2011.

4. Winder T and Lenz HJ: Molecular predictive and prognostic markers in colon cancer. Cancer Treat Rev 36: 550-556, 2010

5. Vanhoefer U, Harstrick A, Achterrath W, Cao S, Seeber S and Rustum YM: Irinotecan in the treatment of colorectal cancer: Clinical overview. J Clin Oncol 19: 1501-1518, 2001.

6. Xu Y and Villalona-Calero MA: Irinotecan: Mechanisms of tumor resistance and novel strategies for modulating its activity. Ann Oncol 13: 1841-1851, 2002.

7. Allen WL, Coyle VM and Johnston PG: Predicting the outcome of chemotherapy for colorectal cancer. Curr Opin Pharmacol 6: 332-336, 2006.

8. Leslie EM, Deeley RG and Cole SP: Multidrug resistance proteins: Role of P-glycoprotein, MRP1, MRP2, and BCRP (ABCG2) in tissue defense. Toxicol Appl Pharmacol 204: 216-237, 2005.

9. Han B and Zhang JT: Multidrug resistance in cancer chemotherapy and xenobiotic protection mediated by the half ATP-binding cassette transporter ABCG2. Curr Med Chem Anticancer Agents 4: 31-42, 2004.

10. Benderra Z, Faussat AM, Sayada L, Perrot JY, Tang R, Chaoui D, Morjani H, Marzac C, Marie JP and Legrand O: MRP3, BCRP, and P-glycoprotein activities are prognostic factors in adult acute myeloid leukemia. Clin Cancer Res 11: 7764-7772, 2005.

11. Burger H, Foekens JA, Look MP, Meijer-van Gelder ME, Klijn JG, Wiemer EA, Stoter G and Nooter K: RNA expression of breast cancer resistance protein, lung resistance-related protein, multidrug resistance-associated proteins 1 and 2, and multidrug resistance gene 1 in breast cancer: Correlation with chemotherapeutic response. Clin Cancer Res 9: 827-836, 2003.

12. Friedrich RE, Punke $C$ and Reymann A: Expression of multi-drug resistance genes (mdrl, mrpl, bcrp) in primary oral squamous cell carcinoma. In Vivo 18: 133-147, 2004.

13. Tsunoda S, Okumura T, Ito T, Kondo K, Ortiz C, Tanaka E, Watanabe G, Itami A, Sakai Y and Shimada Y: ABCG2 expression is an independent unfavorable prognostic factor in esophageal squamous cell carcinoma. Oncology 71: 251-258, 2006. 
14. Kim YH, Ishii G, Goto K, Ota S, Kubota K, Murata Y, Mishima M, Saijo N, Nishiwaki Y and Ochiai A: Expression of breast cancer resistance protein is associated with a poor clinical outcome in patients with small-cell lung cancer. Lung Cancer 65: 105-111, 2009.

15. Robey RW, To KK, Polgar O, Dohse M, Fetsch P, Dean M and Bates SE: ABCG2: A perspective. Adv Drug Deliv Rev 61: 3-13, 2009.

16. Gupta N, Martin PM, Miyauchi S, Ananth S, Herdman AV, Martindale RG, Podolsky R and Ganapathy V: Down-regulation of BCRP/ABCG2 in colorectal and cervical cancer. Biochem Biophys Res Commun 343: 571-577, 2006.

17. Candeil L, Gourdier I, Peyron D, Vezzio N, Copois V, Bibeau F, Orsetti B, Scheffer GL, Ychou M, Khan QA, et al: ABCG2 overexpression in colon cancer cells resistant to SN-38 and in irinotecan-treated metastases. Int J Cancer 109: 848-854, 2004.

18. Muro K, Boku N, Shimada Y, Tsuji A, Sameshima S, Baba H, Satoh T, Denda T, Ina K, Nishina T, et al: Irinotecan plus S-1 (IRIS) versus fluorouracil and folinic acid plus irinotecan (FOLFIRI) as second-line chemotherapy for metastatic colorectal cancer: A randomised phase $2 / 3$ non-inferiority study (FIRIS study). Lancet Oncol 11: 853-860, 2010.

19. Eisenhauer EA, Therasse P, Bogaerts J, Schwartz LH, Sargent D, Ford R, Dancey J, Arbuck S, Gwyther S, Mooney M, et al: New response evaluation criteria in solid tumours: Revised RECIST guideline (version 1.1). Eur J Cancer 45: 228-247, 2009.

20. Kobayashi H: Development of a new in vitro chemosensitivity test using collagen gel droplet embedded culture and image analysis for clinical usefulness. Recent Results Cancer Res 161: 48-61, 2003.

21. Sinicrope FA, Ruan SB, Cleary KR, Stephens LC, Lee JJ and Levin B: Bcl-2 and p53 oncoprotein expression during colorectal tumorigenesis. Cancer Res 55: 237-241, 1995.

22. Hosmer DW and Lemeshow S: Applied Logistic Regression. Shewhart WA and Wilks SS (eds). 2nd edition. John Wiley \& Sons, Inc., New York, pp31-46, 2000.

23. Kawabata S, Oka M, Shiozawa K, Tsukamoto K, Nakatomi K, Soda H, Fukuda M, Ikegami Y, Sugahara K, Yamada Y, et al: Breast cancer resistance protein directly confers SN-38 resistance of lung cancer cells. Biochem Biophys Res Commun 280 : 1216-1223, 2001

24. Robey RW, Ierano $C$, Zhan $Z$ and Bates SE: The challenge of exploiting ABCG2 in the clinic. Curr Pharm Biotechnol 12: 595-608, 2011
25. Mo W and Zhang JT: Human ABCG2: Structure, function and its role in multidrug resistance. Int J Biochem Mol Biol 3: 1-27, 2012.

26. Dietrich CG, Vehr AK, Martin IV, Gassler N, Rath T, Roeb E, Schmitt J, Trautwein C and Geier A: Downregulation of breast cancer resistance protein in colon adenomas reduces cellular xenobiotic resistance and leads to accumulation of a food-derived carcinogen. Int J Cancer 129: 546-552, 2011.

27. Glasgow SC, Yu J, Carvalho LP, Shannon WD, Fleshman JW and McLeod HL: Unfavourable expression of pharmacologic markers in mucinous colorectal cancer. Br J Cancer 92: 259-264, 2005.

28. Xiang L, Su P, Xia S, Liu Z, Wang Y, Gao P and Zhou G: ABCG2 is associated with HER-2 expression, lymph node metastasis and clinical stage in breast invasive ductal carcinoma. Diagn Pathol 6: 90, 2011

29. Jin $Y$, Bin ZQ, Qiang H, Liang C, Hua C, Jun D, Dong WA and Qing L: ABCG2 is related with the grade of glioma and resistance to mitoxantone, a chemotherapeutic drug for glioma. J Cancer Res Clin Oncol 135: 1369-1376, 2009.

30. Gongora C, Vezzio-Vie N, Tuduri S, Denis V, Causse A, Auzanneau C, Collod-Beroud G, Coquelle A, Pasero P, Pourquier P, et al: New Topoisomerase I mutations are associated with resistance to camptothecin. Mol Cancer 10: 64 2011.

31. Del Rio M, Molina F, Bascoul-Mollevi C, Copois V, Bibeau F, Chalbos P, Bareil C, Kramar A, Salvetat N, Fraslon C, et al: Gene expression signature in advanced colorectal cancer patients select drugs and response for the use of leucovorin, fluorouracil, and irinotecan. J Clin Oncol 25: 773-780, 2007.

32. Lansiaux A, Bras-Goncalves RA, Rosty C, Laurent-Puig P, Poupon MF and Bailly C: Topoisomerase I-DNA covalent complexes in human colorectal cancer xenografts with different p53 and microsatellite instability status: Relation with their sensitivity to CTP-11. Anticancer Res 21: 471-476, 2001.

33. Paradiso A, Xu J, Mangia A, Chiriatti A, Simone G, Zito A, Montemurro S, Giuliani F, Maiello E and Colucci G: Topoisomerase-I, thymidylate synthase primary tumour expression and clinical efficacy of 5-FU/CPT-11 chemotherapy in advanced colorectal cancer patients. Int J Cancer 111: 252-258, 2004. 